\title{
EFFECTIVENESS OF AHP IN THERMAL COMFORT ASSESSMENT THROUGH PASSIVE DESIGN ALLOCATION IN TROPICAL SCHOOL OFFICES
}

\author{
Chan Siew Chong \\ Faculty of Science, Technology, Engineering and Mathematics (FOSTEM) \\ INTI International University \\ Nilai, Negeri Sembilan Darul Khusus, Malaysia \\ E-mail: siewchong.chan@newinti.edu.my \\ Yeaw Win Shyang \\ Faculty of Science, Technology, Engineering and Mathematics (FOSTEM) \\ INTI International University \\ Nilai, Negeri Sembilan Darul Khusus, Malaysia \\ E-mail: winshyang.yeaw@newinti.edu.my
}

\begin{abstract}
Since global environmental issues are widely discussed nowadays, a number of studies are being carried out to resolve the challenges of reducing energy usage in buildings, especially related to energy use to sustain the indoor thermal comfort level. In order to tackle the fundamental problems effectively, a comprehensive investigation tool is crucial to identify the comparative related factors and provide solutions according to their priority. Among the methodologies used, Analytical Hierarchy Process (AHP) is commonly used to study the problems with multiple influencing factors which consist of different degree of implications. In this study, this model is used to investigate the effectiveness and consistency of respondents' feedback onto the utility of passive design features in office buildings in order to sustain the indoor thermal comfort levels besides depending on artificial cooling equipment. A number of 413 academic staff from 20 units of primary schools within urban and rural areas in Seremban District were involved in the study. All the schools were equipped with passive design elements, but different types of mechanical ventilation systems were installed in particular schools. Questionnaires with Likert scales were distributed to assist the respondents rank their subjective opinions with objective numerical values. The outputs of rankings generated through AHP by different batches of the respondents were studied, and its consistency were further analysed with t-distribution tests to justify the consistency of the findings. The results showed that there is a quite significant differences among the evaluated batches, and thus, additional studies are much needed to link with unidentified environmental and physical factors, and further integration between evaluation systems.
\end{abstract}

Keywords: Analytical Hierarchy Process, Passive Design, Indoor Thermal Comfort Level. 


\section{Introduction}

As nowadays, the owners or users of buildings are increasingly awaked of the importance of the high performance office buildings, such as a healthy working environment to stimulate the enthusiasm of employees, the building designers and operation managers are thus required to look into different types of strategies to enhance the building operation performance in order to further the buildings' functions.

In Malaysia current practice, the thermal comfort requirements can only be fulfilled with the usage of air conditioning system which requires higher energy input (Moujalled et al 2008). However, due to the crisis of employment and heat issues more serious lately, so there are many discoveries to support for the use of natural ventilation because the positive effects obtained are much more encouraging if compared with use of mechanical ventilation (Gratia et al 2004; Moujalled et al 2008).

In this study, AHP is used to study the reliability and consistency of thermal comfort assessment based on preference ranking of passive design identified in school office buildings. Further justification is made onto the effectiveness of AHP with t-distribution in order to evaluate the suitability of AHP application in these complicated case study.

\section{Literature Review}

In order to produce a building which is able bring benefits to human without creating significant negative impacts to the environment, the design and construction approach of sustainable building is becoming overwhelming in the construction industry as this innovative development trend at the time being is believed to be able to solve the problem of energy use in buildings in the long run ( Holmas \& Hacker , 2007 ; Blengini \& Carlo , 2010 ).

As energy use for ventilation is biggest component in building, therefore one of the key strategy to reduce energy consumption the building is through the use of natural ventilation. However this design approach is to fulfill the needs of human thermal comfort in building. Therefore, a new equilibrium point of total satisfaction must be achieved in order to benefit all parties.

However, the target is not easy to be achieved because this includes a lot of efforts to assess the effectiveness of the passive design in the process of producing a standardized and unique measurable output will thus become more complicated ( Yang et al 2005 ; Yin et al 2010). This is because building has its own characteristics based on both internal and external factors, and the final outcomes may not be the easy solutions for others ( Ong 1997).

Analytical Hierarchy Process (AHP) is used as this model is able to deal with cases with complicated and different characteristics of factors, but it also able to produce consistent outputs after adjusting with Egen factor (Carey \& Glenn 2007). Though this process the complicated and subjective input can be modified to measured and objective outputs to be used in the subsequent analysis. (S.C.Chan et al 2012). 
In order to further justify the effectiveness of AHP to resolve the issues of thermal comfort subject to passive design allocation to optimize natural ventilation, therefore a research is carried to study the feedback of respondents in school office buildings in Seremban District.

\section{Hypotheses/Objectives}

The objective of the study is to justify the effectiveness of AHP to identify correlationships between hierarchical rankings of passive design elements onto the extent of thermal comfort level within office space. The output of this findings is used to further validate the effectiveness of passive design to optimize the natural ventilation utility in office buildings. Thus the hypothesis to be included in this papers consists of:

1. Allocation passive design elements do have significant implication onto the thermal satisfaction levels of the building occupants.

2. Allocation passive design elements do have implication onto the natural ventilation performance in buildings.

\section{Research Design/Methodology}

Traditional AHP is used to justify the outcomes of the findings. However, a number of 413 respondents from 20 schools in both urban and rural areas within Seremban District were involved in the study. Questionnaires with Likert scales (ranged from 0 to 9) were given, and selected interviews were conducted to obtain some backgrounds from the site studied. Basically the process of operation were divided into two main stages:

1. Feedback Stage - All the scaled feedbacks were given appropriate weightage and ranged in the spreadsheet according to AHP principles. Since there are a number of 20 schools, thus there are 20 files to be integrated and averaged out before transferred the combined weightage to the following stages.

2. Evaluation Stage - all the data transferred from the Feedback Stage will be testified using hypothesis test in this stage. Since the population for each school is not more than 50 persons, thus student t-distribution is used to generate and justify the critical values in order to either accept or reject the statements that have been made is Section 3 above.

\section{Data/Model Analysis}

The process starts from collecting the scaled feedbacks from respondents and categorize the data based on different school batches. In each batch of respondents, the data were internalized adjusted using Egen Vector before exporting the data out in the common file to be further integrated to get the key weightages of ranking. 
IJAHP Article: Mu, Saaty/A Style Guide for Paper Proposals To Be Submitted to the International Symposium of the Analytic Hierarchy Process 2014, Washington D.C., U.S.A.

The t-distribution was used to justify the claims of hypothesis. Comparisons among the batches of samples with the key weightage were conducted in order to obtain the consistency of output based on AHP analysis. The formula of t-distribution was summarized as follows:

$t \equiv \frac{\bar{x}-\mu}{s / \sqrt{N}}$,

where $\underline{\mathrm{x}}=$ sample mean, $\mu=$ population mean, $\mathrm{s}=$ standard deviation and $\mathrm{N}=$ number of sample.

The summary of the research design operation can be summarised as follows:

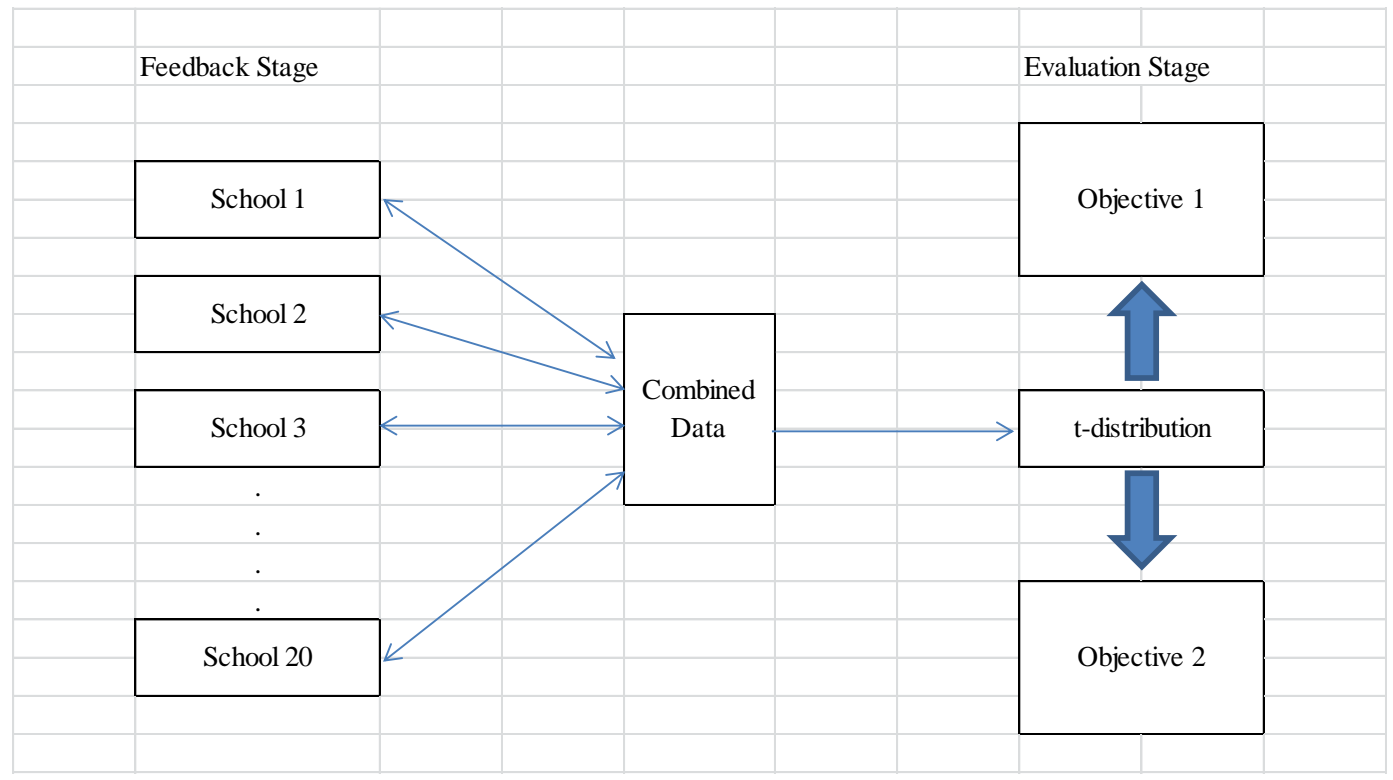

Figure 1 - Operation Process of Research Design

\section{Limitations}

This research model is believed to be able handle the subjective characteristics of data, such as thermal comfort and air flow pattern to produce an objective output, such as number and sizes of passive design. However, there are a number of limitations to be resolved in the future if the similar nature of research topics is to be conducted. The limitations found relevant are listed as follows:

1. The density, location and types of activities carried out in the buildings may be more variety and do have certain implications onto the validity of the findings as mentioned in the research. 
IJAHP Article: Mu, Saaty/A Style Guide for Paper Proposals To Be Submitted to the International Symposium of the Analytic Hierarchy Process 2014, Washington D.C., U.S.A.

2. The influence of the environmental factors may have certain effects onto the setting of thermal comfort levels in the buildings. However, the issue of surrounding is not fully assessed in this research, and thus, need more detailed study onto this section in the near future.

3. This study can be more conclusive if different types of respondent with diverse occupations, ages, and cultures are involved. Different preference and requirements from these respondents may pose more challenges onto the efforts to study the AHP application in this industry.

\section{Conclusions}

In this study, it helps the readers and future researchers to 'open the eyes' to justify the usefulness of AHP in construction and design industry which need to deal with different and changing requirements not only from the perspective of human demands but also from the environment aspects. The characteristics of AHP do help to simplify and resolve the complicated and inconsistent data with more standardized and concrete output. However, this model should be further expand to integrate with other related statistical models, as such hypothesis test and correlation of coefficient, in order to provide a more comprehensive framework to ensure the outputs of the analysis can be tested and implemented to benefit all parties in the near future. This research paper can be considered provide a good platform to start with.

\section{Key References}

Moujalled, B., Richard, C. \& Gerard, G. (2008). Comparison of Thermal Comfort Algorithms in Naturally Ventilated Office Buildings. Energy and Buildings, 40(12), 2215-2223

Gratia, E \& Andre, H. (2004). Is day natural ventilation still possible in office buildings with a double-skin façade? Building and Environment, 39(4), 399-409

Holmes, M.J. \& Hacker, J.N. (2007). Climate change, thermal comfort and energy: Meeting the design challenges of the 21st century. Energy and Buildings 39(7), 802-814

Carey, H \& Glenn, M. (2007). The Analytic Hierarchy Process. The Nineteenth Symposium on Quality Function Deployment, 137-149.

\section{Appendices}

Occasionally, you may want to include appendices such as a survey sample (if data was collected via survey), a picture (e.g. a particular geographical site), etc. Appendices are not needed but if you believe they can improve the readability of your submission, they can be included here provided the total number of pages for your submission does not go above the limit indicate in the first page (short abstract). 